Int. J. Electrochem. Sci., 15 (2020) $2806-2821$

International Journal of

ELECTROCHEMICAL

SCIENCE

www.electrochemsci.org

\title{
Bi-functional S-Doped Ni Catalysts on Copper Foams with Enhanced Electrocatalytic Performance and Excellent Stability for Electrocatalytic Water Splitting
}

\author{
Suyang Feng ${ }^{1}$, Ruidong $\mathrm{Xu}^{1,2, *}$, Xuanbing Wang ${ }^{1}$, Wenbin Wang ${ }^{2}$, Chen Chen ${ }^{2}$, Ao Ju ${ }^{2}$, \\ Ying Zhang ${ }^{2}$,Yan $\mathrm{Ju}^{2}$ \\ ${ }^{1}$ State Key Laboratory of Complex Nonferrous Metal Resources Clean Utilization, Kunming \\ University of Science and Technology, Kunming 650093, China \\ ${ }^{2}$ Faculty of Metallurgical and Energy Engineering, Kunming University of Science and Technology, \\ Kunming 650093, China \\ "E-mail: rdxupaper@aliyun.com
}

doi: $10.20964 / 2020.03 .58$

Received: 20 October 2019 / Accepted: 29 December 2019 / Published: 10 February 2020

The low-cost and energy-efficient catalysts for water splitting are crucial for the sustainable development and renewable energy. The abundant reserves of nickel sulfides have been expected to serve as the precious metal-free materials for the oxygen evolution reaction (OER) or hydrogen evolution reaction (HER). In this research, a bi-functional S-doped Ni films on three-dimensional (3D) porous copper foams (marked as $\mathrm{NiS}_{\mathrm{x}} / \mathrm{CF}$ ) were prepared by a one-step potentiostatic electrodeposition approach in an ethaline solution containing $40 \mathrm{mmol} \mathrm{NiCl}_{2} \cdot 6 \mathrm{H}_{2} \mathrm{O}$ and $20 \mathrm{mmol} \mathrm{CH}_{4} \mathrm{~N}_{2} \mathrm{~S}$. The phase structures, surface elemental valence state, and surface microstructures were observed by X-ray diffraction (XRD), X-ray photoelectron spectrum (XPS), and field-emission scanning electron microscope (FE-SEM). The electrocatalytic performances were measured by linear sweep voltammetry (LSV), Cyclic Voltammetry (CV), Electrochemical impedance spectra (EIS) and ISTEP Multi-Current Steps. The doping of S into $\mathrm{Ni}$ grains and three-dimensional porous structure were found to induce more abundant active sites, significantly improving the water splitting electrolytic activity in alkaline media The $\mathrm{NiS}_{\mathrm{x}} / \mathrm{CF}$ catalyst exhibits the lowest overpotential of OER with $302 \mathrm{mV}$ at $20 \mathrm{~mA} \cdot \mathrm{cm}^{-2}$ and the lowest overpotential of HER with $146 \mathrm{mV}$ at $10 \mathrm{~mA} \cdot \mathrm{cm}^{-2}$. When used in electrocatalytic water splitting, it displays a low cell voltage usage of $1.532 \mathrm{~V}$ at $20 \mathrm{~mA} \mathrm{~cm}^{-2}$ in $1 \mathrm{M} \mathrm{KOH}$. Furthermore, it maintained excellent stability under multiple potentials. Therefore, this research offers a simple synthesis route to fabricate precious metalfree OER and HER Bi-functional catalysts for electrocatalytic water splitting.

Keyword: S-doped Ni; copper foam; catalyst; electrocatalytic activity; electrocatalytic water splitting 


\section{FULL TEXT}

(C) 2020 The Authors. Published by ESG (www.electrochemsci.org). This article is an open access article distributed under the terms and conditions of the Creative Commons Attribution license (http://creativecommons.org/licenses/by/4.0/). 